\title{
Efektivitas Inokulasi Cendawan Mikoriza Arbuskula (CMA) terhadap Produksi Bawang Merah dengan Teknik Pengairan Berbeda
}

\author{
Effectivity of Arbuscular Mycorrhizal Fungi Inoculation on Yield of Shallot Bulb \\ with Different Irrigation Technique
}

\author{
Ismail Saleh $^{1^{*}}$ dan Ida Setya Wahyu Atmaja ${ }^{1}$
}

Diterima 10 April 2017/Disetujui 10 Juli 2017

\begin{abstract}
The purpose of this research was to investigate the effectivity of arbuscular mycorrhizal fungi $(A M F)$ inoculation on shallot yield with three techniques of irrigation. This research was conducted at Gagasari Village, Cirebon from May to August 2016. This research was arranged in split plot design with two factors. Irrigation technique as main plot consisted of three levels i.e. without water logging, intermittent, and using water logging. Rates of AMF as sub plot consisted of three levels i.e., 0,10 , and $15 \mathrm{~g}$ per plant. The result showed that rates of AMF affected water content of plant. The rates $15 \mathrm{~g}$ per plant of AMF gave the highest of water content of plant (65\%). Furthermore, the highest of biomass was resulted by water logging treatment. Phosphorus content of plant was not affected by $A M F$ inoculation. Inoculation of AMF increased shallot bulb weight per plant when it was combined to intermittent and water logging treatment. Based on regression test to AMF rates at water logging treatment, the optimum rates to increase weight of shallot bulb was $6.71 \mathrm{~g}$ AMF per plant. That rates potentially gave $23.53 \mathrm{~g}$ per plant of shallot bulb.
\end{abstract}

Keywords: intermittent, phosphorus content, water content, water logging

\begin{abstract}
ABSTRAK
Penelitian ini bertujuan untuk mengetahui efektivitas dari inokulasi cendawan mikoriza arbuskula (CMA) terhadap produksi bawang merah dengan tiga teknik pengairan yang berbeda. Hifa CMA dapat membantu proses penyerapan air dan unsur hara pada tanaman terutama fosfor $(\mathrm{P})$. Penelitian ini dilaksanakan di Desa Gagasari, Kabupaten Cirebon dari bulan Mei sampai Agustus 2016. Terdapat dua faktor perlakuan yang disusun dengan rancangan split plot. Petak utama adalah teknik pengairan yang terdiri atas tiga taraf yaitu selalu tergenang, intermittent, dan tidak tergenang. Anak petak adalah dosis CMA yang terdiri atas tiga taraf yaitu tanpa CMA, $10 \mathrm{~g}$ per tanaman, dan $15 \mathrm{~g}$ per tanaman. Hasil penelitian menunjukkan bahwa terdapat pengaruh yang nyata dosis CMA terhadap kadar air tanaman. Kadar air tanaman tertinggi (65\%) diperoleh dari pemberian dosis $15 \mathrm{~g}$ per tanaman. Serapan P tanaman tidak dipengaruhi oleh penambahan CMA. Bobot kering tanaman tertinggi (20.23 g per tanaman) diperoleh dari perlakuan teknik pengairan dengan penggenangan. Inokulasi CMA efektif meningkatkan bobot umbi per tanaman pada teknik pengairan intermittent dan selalu tergenang. Berdasarkan hasil uji regresi terhadap dosis CMA pada kondisi selalu tergenang, dosis optimum untuk meningkatkan bobot umbi per tanaman yaitu $6.71 \mathrm{~g} \mathrm{CMA}$ per tanaman. Dari dosis tersebut diperoleh potensi bobot umbi per tanaman $23.53 \mathrm{~g}$ per tanaman.
\end{abstract}

Kata kunci: intermittent, kadar air, penggenangan, serapan $\mathrm{P}$

${ }^{1}$ Program Studi Agroteknologi, Fakultas Pertanian, Universitas Swadaya Gunung Jati

Cirebon, Jawa Barat, 45132, Indonesia

email: ismail.saleh68@gmail.com (*penulis korespondensi) 


\section{PENDAHULUAN}

Bawang merah (Allium ascalonicum) merupakan salah satu komoditas unggulan hortikultura yang banyak dimanfaatkan oleh masyarakat Indonesia. Selain dapat digunakan sebagai bumbu masakan, bawang merah dapat digunakan sebagai obat seperti penurun kolesterol (Ismawati et al., 2012) dan penurun gula darah (Kairupan et al., 2015). Teknik budidaya yang tepat dan dengan memperhatikan faktor lingkungan yang memengaruhi pertumbuhan tanaman seperti ketersediaan air dibutuhkan untuk menghasilkan produk bawang merah yang berkualitas. Air irigasi memegang peranan penting untuk tanaman bawang merah. Fauziah et al. (2016) menambahkan bahwa penurunan volume irigasi pada tanaman bawang menyebabkan berkurangnya bobot panen total.

Teknik pengairan atau pemberian air yang dilakukan petani pada umumnya adalah dengan menyiram tanaman menggunakan gembor dan menggunakan sistem leb (penggenangan) pada parit antar bedengan. Sistem ini sangat tergantung pada volume air irigasi. Air menjadi faktor pembatas dalam budidaya bawang merah ketika memasuki musim kemarau. Untuk mengatasi kondisi tersebut diperlukan alternatif teknologi budidaya bawang merah yang membantu petani dalam mengatasi permasalahan penggunaan air. Salah satu teknologi yang diterapkan adalah inokulasi Cendawan Mikoriza Arbuskula (CMA) pada budidaya tanaman bawang merah.

Cendawan Mikoriza Arbuskula (CMA) merupakan simbiosis antara cendawan dengan akar tanaman. CMA hidup di sekitar daerah perakaran tanaman yang memiliki kemampuan meningkatkan resitensi tanaman inang terhadap kondisi kekeringan dengan memodifikasi hubungan tanah dan tanaman serta meningkatkan kapasitas penyerapan air (Echave et al., 2005). Penelitian yang dilakukan oleh Jezdinsky et al. (2012) menunjukkan Cendawan Mikoriza Arbuskula dapat meningkatkan efektivitas penggunaan air (water use efficiency) dan bobot segar tajuk pada spesies Allium porrum dalam kondisi kekeringan. Selain berfungsi untuk membantu penyerapan air, CMA dapat memantapkan agregat dan struktur tanah serta berperan dalam meningkatkan serapan unsur hara terutama fosfor (P) (Fuady, 2013). Pupuk hayati mikoriza yang digunakan dalam penelitian ini menggunakan media zeolit. Mineral zeolit adalah senyawa alumino silikat hidrat dengan logam alkali tanah yang memiliki aerasi dan porositas yang ideal untuk perkembangan mikoriza (Armini et al., 2015). Penelitian ini bertujuan untuk mengetahui efektivitas penambahan pupuk hayati CMA terhadap produksi bawang merah dengan tiga teknik pengairan yang berbeda.

\section{BAHAN DAN METODE}

Penelitian dilaksanakan di Desa Gagasari, Kecamatan Gebang, Kabupaten Cirebon dengan ketinggian tempat 5 meter di atas permukaan laut $(\mathrm{m} \mathrm{dpl})$. Lahan yang digunakan merupakan lahan bekas tanaman padi. Bahan yang digunakan dalam penelitian ini meliputi bibit bawang merah kultivar Bima Brebes, pupuk cendawan mikoriza arbuskula (menggunakan media zeolite), pupuk anorganik NPK, dan insektisida.

Rancangan yang digunakan dalam penelitian ini adalah rancangan split plot dengan petak utama adalah teknik pengairan dan anak petak adalah dosis pupuk CMA. Teknik pengairan yang digunakan antara lain dengan penggenangan parit (tergenang), penggenangan parit secara intermittent, dan tanpa penggenangan. Dosis pupuk CMA yang digunakan yaitu 0,10 , dan $15 \mathrm{~g}$ per tanaman. Sembilan kombinasi perlakuan tersebut diulang tiga kali sehingga terdapat 27 satuan percobaan. Unit percobaan adalah petak dengan luas $1.6 \mathrm{~m}^{2}$. Data dianalisis dengan menggunakan uji $\mathrm{F}$ dan uji lanjut tukey pada taraf 5\%. Data kadar P dianalisis dengan menggunakan uji regresi untuk mengetahui pola respon dari dosis CMA terhadap kadar $\mathrm{P}$ pada tanaman bawang merah.

Bibit bawang merah dipotong bagian ujungnya untuk memudahkan tunas tumbuh. Penanaman bibit bawang merah menggunakan jarak tanam $20 \mathrm{~cm} \times 20 \mathrm{~cm}$. Pengaplikasian pupuk CMA dilakukan saat penanaman dengan cara ditugal di samping umbi yang ditanam. Penyiraman dilakukan dua kali sehari dengan menggunakan gembor. Pengaturan teknik pengairan sesuai perlakuan dilakukan setelah tanaman berumur 2 MST. 
Perlakuan dengan teknik pengairan selalu tergenang yaitu dengan cara menjaga air di parit antar bedengan selalu tersedia. Kedalaman permukaan air yaitu $30 \mathrm{~cm}$ dari permukaan tanah. Penggenangan secara intermittent dilakukan dengan cara memasukkan air ke parit antar bedengan dengan kedalaman $30 \mathrm{~cm}$ dari permukaan tanah kemudian dibiarkan sampai kering. Air kembali dimasukkan setelah air di parit habis.

Peubah yang diamati antara lain bobot kering tanaman, kadar air tanaman, serta serapan $\mathrm{P}$ pada tanaman bawang merah yang dilakukan pada umur 6 MST. Pengamatan kadar air dilakukan dengan metode langsung yaitu mengeringkan tanaman bawang merah dengan menggunakan oven pada suhu $105{ }^{\circ} \mathrm{C}$. Pengukuran serapan $\mathrm{P}$ dilakukan di Balai Penelitian Tanah, Bogor. Pengamatan komponen produksi meliputi jumlah umbi per tanaman, bobot per umbi, kadar air umbi, dan bobot umbi per tanaman.

Pupuk yang digunakan untuk pemupukan tanaman bawang merah menggunakan campuran antara pupuk anorganik tunggal dan majemuk yang mengandung beberapa unsur hara makro dan mikro. Pemupukan dilakukan sebanyak empat kali yaitu pada saat sebelum penanaman, 18.27, dan 34 HST dengan dosis mengikuti kebiasaan petani setempat. Penambahan unsur hara dari pupuk yang diberikan pada setiap waktu pemupukan dapat dilihat pada Tabel 1.

\section{HASIL DAN PEMBAHASAN}

\section{Kondisi Tanah Penelitian}

Hasil analisis tanah sebelum percobaan disajikan pada Tabel 2. Kondisi $\mathrm{pH}$ tanah bersifat netral, kadar $\mathrm{N}$ rendah, $\mathrm{P}_{2} \mathrm{O}_{5}$ sangat tinggi, serta $\mathrm{K}_{2} \mathrm{O}$ tinggi. Tekstur tanah termasuk ke dalam kategori liat.

\section{Kadar Air, Biomassa, dan Kadar P Tanaman Bawang Merah}

Pengamatan pada tanaman bawang merah meliputi bobot kering, kadar air, dan serapan $\mathrm{P}$ tanaman bawang diamati pada saat tanaman berumur 6 MST. Dosis CMA berpengaruh nyata terhadap kadar air tanaman. Peningkatan dosis CMA diikuti oleh peningkatan kadar air tanaman (Tabel 2). Hifa atau miselium yang diproduksi oleh CMA dan bersimbiosis dengan akar tanaman dapat membantu akar dalam menyerap air yang terdapat dalam tanah. Inokulasi tanaman selada dengan beberapa spesies CMA dapat meningkatkan serapan air tanaman dalam kondisi kekeringan (Marulanda et al., 2003). Qian-Sheng dan Ren Xue (2006) menambahkan bahwa perlakuan mikoriza arbuskula dapat meningkatkan potensial air daun, laju transpirasi, laju fotosintesis, konduktansi stomata, dan kadar air relatif pada tanaman jeruk.

Tabel 1. Penambahan unsur hara pada tanaman bawang merah.

\begin{tabular}{|c|c|c|}
\hline Waktu Pemupukan & Unsur Hara & Dosis $\left(\mathrm{kg} \mathrm{ha}^{-1}\right)$ \\
\hline \multirow{3}{*}{$\begin{array}{l}\text { Sebelum Tanam (pengolahan } \\
\text { tanah ke dua) }\end{array}$} & $\mathrm{N}$ & 51.0 \\
\hline & $\mathrm{P}_{2} \mathrm{O}_{5}$ & 127.5 \\
\hline & $\mathrm{K}_{2} \mathrm{O}$ & 19.5 \\
\hline \multirow{4}{*}{$18 \mathrm{HST}$} & $\mathrm{N}$ & 92.6 \\
\hline & $\mathrm{P}_{2} \mathrm{O}_{5}$ & 113.1 \\
\hline & $\mathrm{K}_{2} \mathrm{O}$ & 40.3 \\
\hline & $\mathrm{S}$ & 15.6 \\
\hline \multirow{7}{*}{27 HST } & $\mathrm{N}$ & 105.0 \\
\hline & $\mathrm{P}_{2} \mathrm{O}_{5}$ & 57.3 \\
\hline & $\mathrm{K}_{2} \mathrm{O}$ & 83.1 \\
\hline & $\mathrm{S}$ & 15.6 \\
\hline & $\mathrm{CaO}$ & 17.9 \\
\hline & $\mathrm{Na}$ & 12.6 \\
\hline & B & 0.2 \\
\hline \multirow{4}{*}{$34 \mathrm{HST}$} & $\mathrm{N}$ & 74.7 \\
\hline & $\mathrm{P}_{2} \mathrm{O}_{5}$ & 46.0 \\
\hline & $\mathrm{K}_{2} \mathrm{O}$ & 110.0 \\
\hline & $\mathrm{S}$ & 8.4 \\
\hline
\end{tabular}


Tabel 2. Hasil analisis kesuburan tanah sebelum percobaan

\begin{tabular}{clcc}
\hline No & \multicolumn{1}{c}{ Keterangan } & Nilai & Satuan \\
\hline 1 & $\mathrm{pH} \mathrm{H} \mathrm{H}_{2} \mathrm{O}$ & 7.24 & \\
2 & $\mathrm{pH} \mathrm{KCl}$ & 6.22 & $\%$ \\
3 & $\mathrm{C}($ Walkley dan Black) & 1.11 & $\%$ \\
4 & $\mathrm{~N}(\mathrm{Kjedahl})$ & 0.12 & \\
5 & $\mathrm{C} / \mathrm{N}$ & 9 & $\mathrm{mg} / 100 \mathrm{~g}$ \\
6 & $\mathrm{P}_{2} \mathrm{O}_{5}(\mathrm{HCl} \mathrm{25 \% )}$ & 309 & $\mathrm{ppm}$ \\
7 & $\mathrm{P}_{2} \mathrm{O}_{5}(\mathrm{Olsen})$ & 909 & $\mathrm{mg} / 100 \mathrm{~g}$ \\
8 & $\mathrm{~K}_{2} \mathrm{O}(\mathrm{HCl} \mathrm{25 \% )}$ & 43 & $\mathrm{ppm}$ \\
9 & $\mathrm{~K}_{2} \mathrm{O}(\mathrm{Morgan})$ & 206 & $\%$ \\
10 & Pasir & 3 & $\%$ \\
11 & Debu & 19 & $\%$ \\
12 & Liat & 78 & \\
\hline
\end{tabular}

Bobot kering tanaman lebih dipengaruhi oleh teknik pengairan. Bobot kering tanaman tertinggi $(20.23 \mathrm{~g})$ diperoleh pada teknik pengairan selalu tergenang. Kondisi tidak tergenang memberikan bobot kering terendah dibandingkan dengan perlakuan intermittent dan selalu tergenang (Tabel 3). Teknik pengairan intermittent dan selalu tergenang dapat menyuplai air lebih baik terhadap tanaman bawang merah dibandingkan dengan perlakuan tanpa digenangi. Penurunan bobot kering tanaman gandum akibat cekaman kekeringan ditunjukkan oleh penelitian Boutraa et al. (2010). Respon tumbuhan terhadap kekurangan air dapat dilihat pada aktivitas metabolisme, morfologi, tingkat pertumbuhan atau produktivitas. Pertumbuhan sel merupakan fungsi tanaman yang paling sensitif terhadap kekurangan air (Solichatun et al., 2005).

Kadar P pada tanaman bawang merah tidak dipengaruhi baik oleh dosis CMA maupun teknik pengairan. Hal tersebut diduga karena kadar $\mathrm{P}$ tersedia di lahan penelitian sangat tinggi sehingga peranan CMA dalam penyerapan $\mathrm{P}$ tidak signifikan. Grant et al.
(2005) menyatakan bahwa asosiasi mikoriza menurun apabila kadar $\mathrm{P}$ tersedia tanah meningkat. Secara umum peningkatan dosis CMA memberikan trend yang meningkat terhadap serapan P. Hal tersebut ditunjukkan dari uji regresi dosis CMA terhadap serapan $\mathrm{P}$ yang menunjukkan adanya pola respon linier $\left(\mathrm{P}<0.05, \mathrm{R}^{2}=0.1654\right)$ (Gambar 1). Stein et al. (2008) menyatakan bahwa hifa cendawan mikoriza dapat menyerap dan mengakumulasikan fosfor lebih baik dibandingkan dengan rambut akar. Hasil penelitian Abdelmoneim et al. (2013) juga menyatakan bahwa serapan P pada jagung meningkat dengan adanya penambahan CMA. Effendy dan Wijayani (2008) menyatakan bahwa serapan $\mathrm{P}$ yang lebih tinggi pada tanaman yang diinokulasi oleh CMA disebabkan karena sekresi asam-asam organik seperti asam oksalat dan asam sitrat menyebabkan terjadinya proses pelarutan P-padatan anorganik di zona perakaran menjadi P-tersedia. Margarettha (2010) menyatakan bahwa ketersediaan $P$ tanah meningkat secara signifikan dengan peningkatan jumlah inokulan mikoriza yang diberikan.

Tabel 3. Pengaruh dosis CMA dan teknik pengairan terhadap bobot kering, kadar air, dan serapan $\mathrm{P}$ tanaman bawang merah

\begin{tabular}{|c|c|c|c|c|c|c|c|c|c|}
\hline \multirow{2}{*}{$\frac{\text { Perlakuan }}{\text { Dosis CMA }}$} & \multicolumn{3}{|c|}{ Bobot Kering (g) } & \multicolumn{3}{|c|}{ Kadar Air (\%) } & \multicolumn{3}{|c|}{ Kadar P (\%) } \\
\hline & & & & & & & & & \\
\hline $0 \mathrm{~g}$ per tanaman & $16.42 \mathrm{a}$ & \pm & 4.17 & $55.12 \mathrm{~b}$ & \pm & 4.34 & $0.336 \mathrm{a}$ & \pm & 0.03 \\
\hline $10 \mathrm{~g}$ per tanaman & $17.26 \mathrm{a}$ & \pm & 9.23 & $61.23 \mathrm{ab}$ & \pm & 7.98 & $0.362 \mathrm{a}$ & \pm & 0.05 \\
\hline $15 \mathrm{~g}$ per tanaman & $11.88 \mathrm{a}$ & \pm & 2.91 & $65.00 \mathrm{a}$ & \pm & 4.70 & $0.384 \mathrm{a}$ & \pm & 0.05 \\
\hline Teknik Pengairan & & & & & & & & & \\
\hline Tidak Tergenang & $11.20 \mathrm{~b}$ & \pm & 3.21 & $60.13 \mathrm{a}$ & \pm & 6.37 & $0.349 \mathrm{a}$ & \pm & 0.04 \\
\hline Intermittent & $14.12 \mathrm{ab}$ & \pm & 5.35 & $62.45 \mathrm{a}$ & \pm & 8.71 & $0.374 \mathrm{a}$ & \pm & 0.07 \\
\hline Tergenang & $20.23 \mathrm{a}$ & \pm & 7.52 & $58.83 \mathrm{a}$ & \pm & 6.08 & $0.359 \mathrm{a}$ & \pm & 0.04 \\
\hline
\end{tabular}

Keterangan: Angka yang diikuti oleh huruf yang sama pada kolom yang sama menunjukkan tidak berbeda nyata menurut uji Tukey pada taraf 5\%. Angka diikuti oleh \pm standar deviasi. 


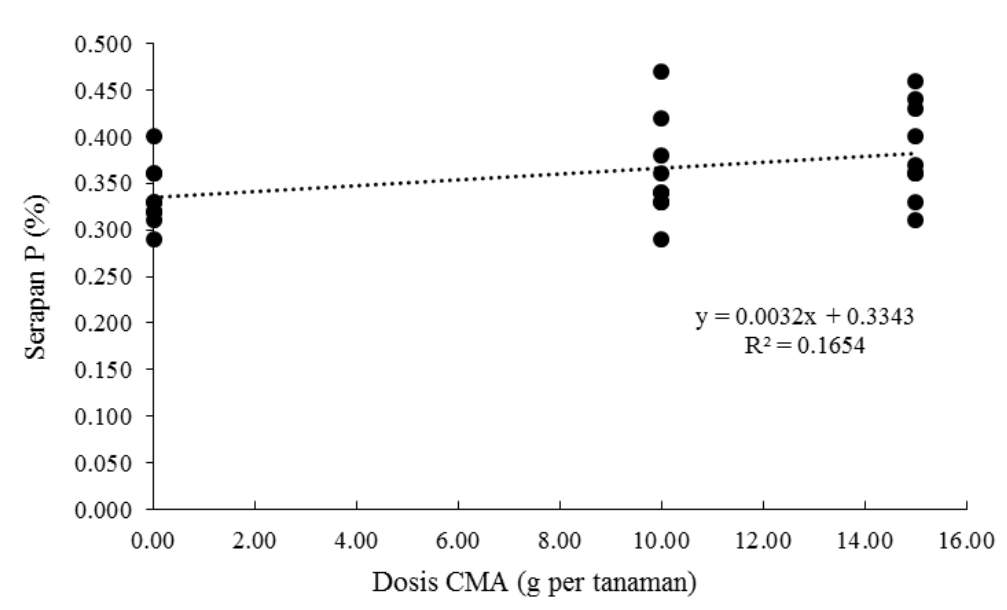

Gambar 1. Kurva regresi dosis CMA terhadap serapan P

\section{Komponen Hasil dan Produksi Bawang Merah}

Dosis CMA dan teknik pengairan tidak berpengaruh nyata terhadap semua komponen hasil tanaman bawang merah yang meliputi jumlah umbi per tanaman, bobot per umbi, dan diameter umbi (Tabel 4). Tidak terdapat interaksi antara pemberian dosis CMA dengan teknik pengairan.
Pengaruh interaksi antara dosis CMA dengan teknik pengairan ditemukan pada peubah bobot umbi per tanaman. Perlakuan dosis CMA berpengaruh terhadap bobot umbi per tanaman pada teknik pengairan intermittent dan tergenang. Teknik pengairan tidak berpengaruh nyata pada semua taraf dosis CMA terhadap bobot umbi per tanaman (Tabel 5).

Tabel 4. Pengaruh dosis CMA dan teknik pengairan terhadap komponen hasil tanaman bawang merah

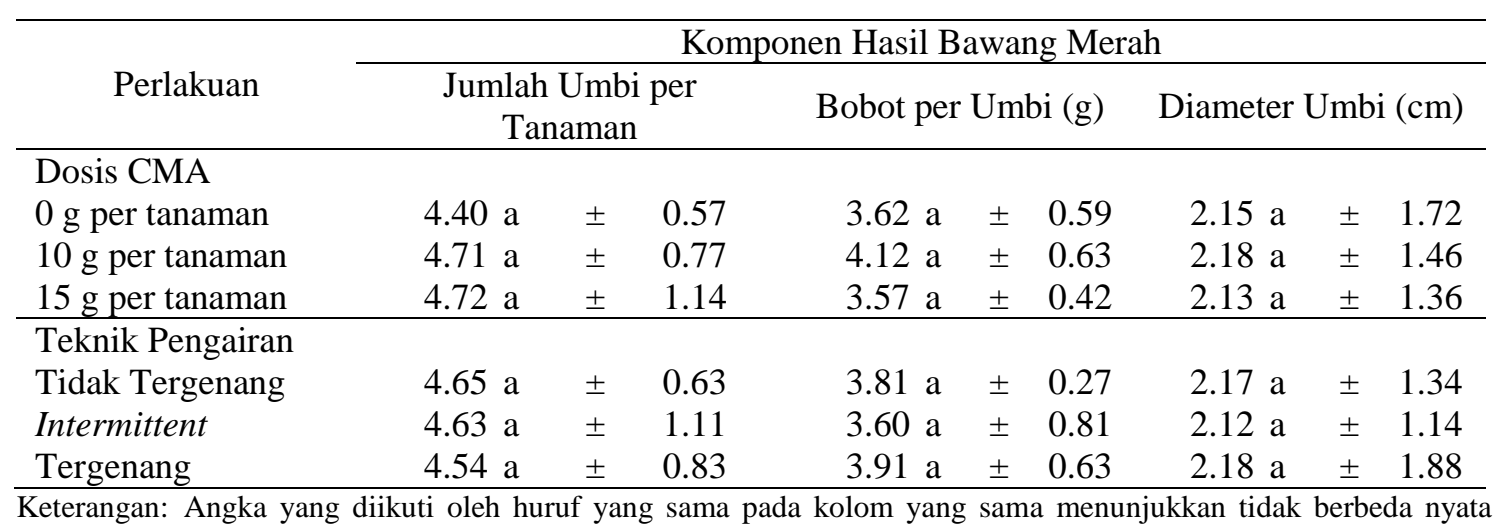
menurut uji Tukey pada taraf 5\%. Angka diikuti oleh \pm standar deviasi.

Tabel 5. Pengaruh interaksi antara dosis CMA dengan teknik pengairan terhadap bobot umbi per tanaman

\begin{tabular}{|c|c|c|c|c|c|c|}
\hline \multirow{2}{*}{ Perlakuan } & \multicolumn{6}{|c|}{ Bobot Umbi per Tanaman (g) } \\
\hline & Tidak Digenangi & \multicolumn{2}{|c|}{ Intermitent } & \multicolumn{3}{|c|}{ Tergenang } \\
\hline $0 \mathrm{~g}$ & $16.75 \mathrm{a} \pm 0.72 \mathrm{~A}$ & $13.38 \mathrm{~b}$ & $\pm 2.52 \mathrm{~A}$ & $17.17 \mathrm{ab}$ & \pm & 2.60 \\
\hline $10 \mathrm{~g}$ per tanam & $18.00 \mathrm{a}$ & $17.97 \mathrm{a}$ & $2.63 \mathrm{~A}$ & $21.70 \mathrm{a}$ & \pm & $1.04 \mathrm{~A}$ \\
\hline $15 \mathrm{~g}$ per tanaman & $18.23 \mathrm{a}$ & $17.35 \mathrm{ab}$ & $2.56 \mathrm{~A}$ & $14.04 \mathrm{~b}$ & \pm & $0.70 \mathrm{~A}$ \\
\hline
\end{tabular}

Keterangan: Angka yang diikuti oleh huruf kapital yang sama pada baris yang sama serta huruf kecil pada kolom yang sama menunjukkan tidak berbeda nyata menurut uji Tukey pada taraf 5\%. Angka diikuti oleh \pm standar deviasi. 
Dosis CMA yang berpengaruh nyata terhadap bobot umbi per tanaman dalam kondisi penggenangan intermittent atau selalu tergenang menunjukkan bahwa ketersediaan air berpengaruh terhadap aktivitas CMA dalam tanah. Kondisi stres air menurunkan persentase kolonisasi cendawan mikoriza arbuskula sehingga peranan dari CMA menjadi berkurang seperti yang dilaporkan oleh Gong et al. (2015) pada tanaman jewawut. Kondisi kekeringan menghambat perkecambahan spora dan penyebaran dari miselium CMA. Selain itu, kondisi kekeringan menurunkan pertumbuhan akar bawang merah sehingga penyerapan unsur hara juga akan terhambat (Swasono, 2012).

Pemberian dosis CMA $10 \mathrm{~g}$ per tanaman meningkatkan bobot umbi per tanaman dibandingkan dengan tanpa pemberian CMA. Hasil penelitian Murniati et al. (2008) menunjukkan bahwa inokulasi CMA sebanyak $10 \mathrm{~g}$ per tanaman yang dikombinasikan dengan $5 \mathrm{~kg} \mathrm{CuSO}_{4} \mathrm{ha}^{-1}$ memberikan hasil umbi bawang merah terbaik pada lahan gambut. Peningkatan produksi umbi bawang merah akibat pemberian CMA ini juga ditunjukkan oleh penelitian Sumiati dan Gunawan (2006) dan Shuab et al. (2014).

Bobot umbi per tanaman cenderung menurun ketika dosis CMA ditingkatkan dari $10 \mathrm{~g}$ menjadi $15 \mathrm{~g}$ per tanaman terutama pada teknik pengairan selalu tergenang. Berdasarkan hasil uji regresi terhadap dosis CMA diperoleh bahwa pemberian CMA memberikan respon kuadratik terhadap bobot umbi per tanaman $\quad(\mathrm{P}<0.01)$ pada kondisi selalu tergenang (Gambar 2).

Dosis optimum CMA untuk teknik pengairan selalu tergenang yang diperoleh dari persamaan kuadratik tersebut adalah $6.71 \mathrm{~g}$ per tanaman. Potensi hasil umbi bawang merah yang diperoleh dari dosis tersebut adalah 23.53 g per tanaman. Peningkatan dosis CMA dari dosis optimum akan menurunkan potensi hasil. hal ini disebabkan bahwa CMA dalam bersimbiosis dengan tanaman juga membutuhkan karbohidrat yang diperoleh dari akar tanaman. Apabila rasio unsur hara yang diserap oleh CMA terhadap karbohidrat yang dibutuhkan lebih kecil, maka akan terjadi penurunan hasil. Taiz dan Zeiger (2002) menyatakan bahwa dalam kondisi tanah yang sangat subur, keberadaan CMA dapat dianggap sebagai patogen oleh tanaman.

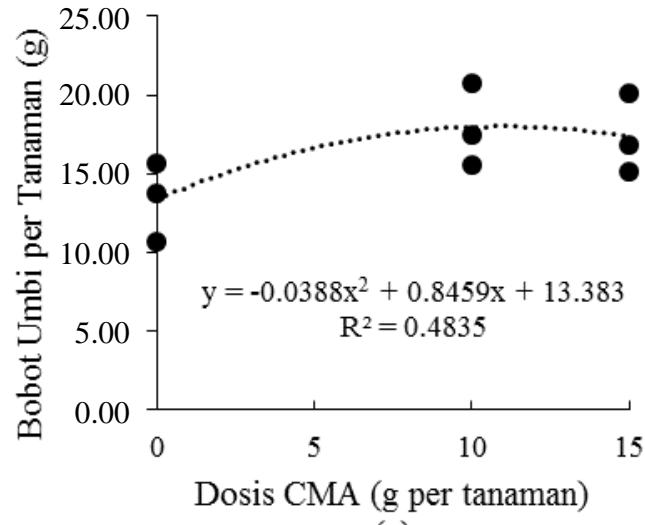

(a)

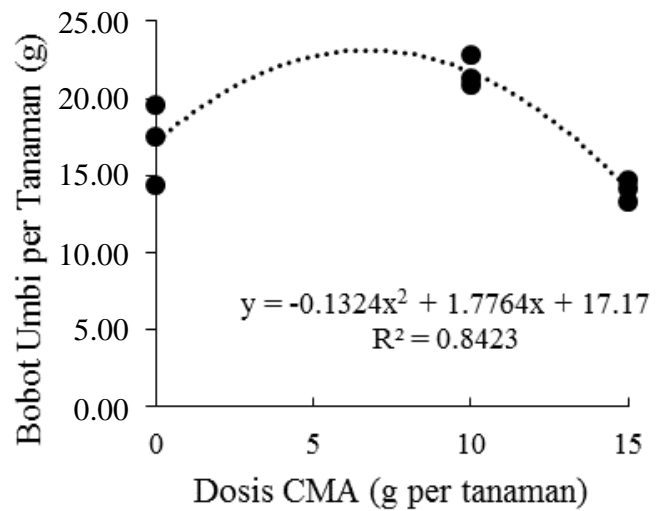

(b)

Gambar 2. Kurva regresi dosis CMA terhadap bobot umbi per tanaman (a) dengan teknik pengairan intermittent (b) dengan teknik pengairan selalu tergenang

\section{KESIMPULAN}

Berdasarkan hasil penelitian dapat disimpulkan bahwa pemberian cendawan mikoriza arbuskula (CMA) pada tanaman bawang merah lebih efektif apabila diberikan dalam kondisi parit antar bedengan tergenang. Berdasarkan hasil uji regresi, dosis optimal CMA yang menghasilkan produksi umbi per tanaman tertinggi yaitu $6.71 \mathrm{~g}$ per tanaman dengan teknik pengairan selalu tergenang. Potensi bobot umbi per tanaman yang diperoleh dari dosis tersebut yaitu $23.53 \mathrm{~g}$ per tanaman. 


\section{UCAPAN TERIMA KASIH}

Penelitian ini didanai oleh Direktur Riset dan Pengabdian Masyarakat Direktorat Jenderal Penguatan Riset dan Pengembangan Kementerian Riset, Teknologi, dan Pendidikan Tinggi Sesuai dengan Surat Perjanjian Penugasan Pelaksanaan Hibah Penelitian Nomor: 105/SP2H/PPM/DRPM/II/2016, tanggal 17 Februari 2016

\section{DAFTAR PUSTAKA}

Abdelmoneim, T.S., T.A.A. Mousa, O.A. Almaghrabi, H.S. Alzahrani, I. Abdelbagi. 2013. Increasing plant tolerance to drought stress by inoculation with arbuscular mychorrhizal fungi. Life Science Journal. 10(4): 3273-3280.

Armini, N.W., I.G.P. Wirawan, I.N. Wijaya. 2015. Identifikasi mikoriza vesicular arbuskular (MVA) dari rhizosfer bawang merah (Allium cepa L.) dan talas (Colocasia esculenta (L.) Schott) serta perbanyakannya menggunakan media zeolite. E-Jurnal Agroekoteknologi Tropika. 4(4): 324-332.

Boutraa, T., A. Akhkha, A.A. Al-Shoaibi, A.M Alhejeli. 2010. Effect of water stress on growth and water use efficiency (WUE) of some wheat cultivars (Triticum durum) grown in Saudi Arabia. J. Taibah University for Science. 3: 39-48.

Echave, M., M. Conti, A. Clua, M. Ruscitti, J. Beltrano. 2005. Responses of mycorrhizal infection in the drought resistance and growth of Lotus glaber. Lotus Newsletter. 35(2): 182-186.

Effendy, M., B.W. Wijayani. 2008. Studi hifa eksternal CMA dalam memahami fungsinya mengkontribusi serapan $\mathrm{P}$ tanaman mengggunakan metode Thin Section. J. Tanah Trop. 13(3): 241-255.

Fauziah, R., A.D. Susila, E. Sulistyono. 2016. Budidaya bawang merah (Allium ascalonicum L.) pada lahan kering menggunakan irigasi sprinkler pada berbagai volume dan frekuensi. J. Hort Indonesia. 7(1): 1-8.

Fuady, Z. 2013. Kontribusi cendawan mikoriza arbuskular terhadap pembentukan agregat tanah dan pertumbuhan tanaman. Lentera. 13(3): 7-15.

Gong, M., X. You, Q. Zhang. 2015. Effect of glomus intaradices on the growth and reactive oxygen metabolism of foxtail millet under drought. Annals of Microbiology. 65(1): 595-602.

Grant, C., S. Bittman, M. Montreal, C. Plenchette, C. Morel. 2005. Soil and fertilizer phosphorus: effects on plant $\mathrm{P}$ supply and mychorrhizal development. Canadian Journal of Plant Science. 85(1): 3-14.

Ismawati, E. Asni, M.Y. Hamidy. 2012. Pengaruh air perasan umbi bawang merah (Allium ascalonicum L.) terhadap malondialdehid (MDA) plasma mencit yang diinduksi hiperkolesterolemia. J. Natur Indonesia. 14(2): 150-154.

Jezdinsky, A., K. Petrikova, K. Slezak, R. Pokluda. 2012. Effect of drought stress and mycorrhizal inoculation on the growth, photosynthetic activity and water use efficiency of leek (Allium porrum L. 'Gigante Suizo). Acta Universitatis Agriculturae et Silviculturae Mendelianae Brunensis. 40(8): 101-108.

Kairupan, B.Y., M.P. Wowor, C. Mambo. 2015. Pengaruh pemberian ekstrak umbi bawang merah (Allium cepa $\mathrm{L}$ ) terhadap kadar gula darah tikus wistar (Rattus norvegicus) yang diinduksi dengan aloksan. Jurnal e-Biomedik. 3(1): 248253.

Margarettha. 2010. Pemanfaatan tanah bekas tambang batubara dengan pupuk hayati mikoriza sebagai media tanam jagung manis. J. Hidrolitan. 1(3): 1-10.

Marulanda, A., R. Azcon, J.M. Ruiz-Lozano. 2003. Contribution of six arbuscular mychorrhizal fungal isolates to water uptake by Lactuca sativa plants under 
drought stress. Physiologia Plantarum. 119: $526-533$

Murniati, A.N. Yulia, F. Silvina. 2008. Peningkatan produksi bawang merah dengan agihan cendawan mikoriza arbuskular dan $\mathrm{Cu}$ pada lahan gambut. SAGU. 7(1): 19-25.

Qiang, S.W., R.X. Xia. 2006. Arbuscular mycorrhizal fungi influence growth, osmotic adjustment and photosynthesis of citrus under well-watered and water stress condition. J. Plant Physiology. 163: $417-425$.

Shuab, R., R. Lone, J. Naidu, V. Sharma, S. Imtiyaz, K.K. Koul. 2014. Benefits of inoculation of arbuscular mychorrhizal fungi on growth and development of onion (Allium cepa) plant. AmericanEurasian J. Agric. \& Environ. Sci. 14(6): 527-535.
Stein, K.R., J.E. Bidlack, S.H. Jansky. 2008. Introductory Plant Biology $11^{\text {th }}$ Edition. McGraw Hill, New York.

Sumiati, E., O.S. Gunawan. 2006. Aplikasi pupuk hayati mikoriza untuk meningkatkan efisiensi serapan unsur hara NPK serta pengaruhnya terhadap hasil dan kualitas umbi bawang merah. J. Hort. 17(1): 34-42.

Swasono, F.D.H. 2012. Karakteristik fisiologi toleransi tanaman bawang merah terhadap cekaman kekeringan di tanah pasir pantai. Jurnal AgriSains. 3(4): 88102.

Taiz, L., E. Zeiger. 2002. Plant Physiology. 3rd edn. Annals of Botany. 91(6): 750751. doi: $10.1093 / \mathrm{aob} / \mathrm{mcg} 079$. 